\title{
Genetic parameters for spiral-grain angle in two 19-year-old clonal Norway spruce trials
}

\author{
Björn Hannrup ${ }^{\mathrm{a}^{*}}$, Michael Grabner ${ }^{\mathrm{b}}$, Bo Karlsson ${ }^{\mathrm{c}}$, Ulrich Müller ${ }^{\mathrm{d}}$, Sabine Rosner ${ }^{\mathrm{b}}$, \\ Lars Wilhelmsson ${ }^{\mathrm{a}}$ and Rupert Wimmer ${ }^{\mathrm{b}}$ \\ ${ }^{\text {a }}$ SkogForsk, Science Park, 75183 Uppsala, Sweden \\ ${ }^{\mathrm{b}}$ Institute of Botany, Universität für Bodenkultur Wien, Gregor Mendelstrasse 33, 1180 Vienna, Austria \\ ${ }^{\mathrm{c}}$ SkogForsk, Ekebo, 26890 Svalöv, Sweden \\ ${ }^{\mathrm{d}}$ Institute of Wood Science and Technology, Universität für Bodenkultur Wien, Gregor Mendelstrasse 33, 1180 Vienna, Austria
}

(Received 16 August 2001; accepted 17 June 2002)

\begin{abstract}
Spiral grain was measured for all annual rings on wood discs taken at a single sampling height from two 19-year-old (field age) Norway spruce (Picea abies (L.) Karst.) clonal trials. In both trials, the mean grain angle reached a maximum inclination to the left at ring number 4 , followed by a monotonic decrease towards a right-handed inclination. Clonal means of mean grain angle of rings 3 to 15 ranged from 0.5 to 4.7 degrees and from -0.2 to 5.3 degrees in the two trials, respectively. The broad-sense heritability of mean grain angle was 0.42 in both trials and the slope of the radial grain-angle development showed heritabilities varying between 0.26 and 0.40 . Estimates of genotypic correlations indicated that clones with a high grain angle in the inner rings tended to have a more rapid development towards a straight angle in the following rings. Selection based on any of the rings in the interval from ring numbers 5 to 10 was most efficient in decreasing the average grain spirality at the sampling level considered.
\end{abstract}

spiral grain / heritability / genotypic correlation / correlated response

Résumé - Paramètres génétiques de l'angle du fil du bois dans 2 tests clonaux d'Épicéa commun âgés de 19 ans. L'angle du fil du bois a été mesuré pour tous les cernes à partir de disques prélevés à la même hauteur dans 2 tests clonaux d'Épicéa commun (Picea abies (L.) Karst.) âgés de 19 ans. Dans les 2 dispositifs, l'angle moyen atteint une inclinaison maximale à gauche au cerne 4. Elle est suivie d'une diminution monotonique de l'angle vers une inclinaison à droite. Les moyennes clonales de l'angle moyen des cernes 3 à 15 s'étalent de 0,5 à 4,7 degrés et de - 0,2 à 5,3 degrés respectivement dans les deux tests. L'héritabilité au sens large de l'angle du fil est de 0,42 dans les 2 essais et la pente de la régression de l'angle sur les cernes annuels présente une héritabilité variant entre 0,26 et 0,40 . Les corrélations génotypiques montrent que les clones avec un angle élevé dans les cernes proches de la moëlle ont tendance à présenter une évolution plus rapide de l'angle vers un angle droit dans les cernes suivants. Une sélection basée sur un des cernes compris entre le $5^{\mathrm{e}}$ et le $10^{\mathrm{e}}$ est apparue plus efficace pour diminuer l'angle moyen du fil au niveau de l'échantillon considéré.

angle du fil / héritabilité / corrélation génotypique / gain génétique

\section{INTRODUCTION}

The term spiral grain is applied to the helical orientation of the tracheids in a tree stem, which gives a twisted appearance to the trunk after the bark has been removed [24]. The spirality may be either right- or left-handed, the slope may be constant in a given tree or may change with age. Spiral grain is a topic of considerable importance to end-users, as grain deviation from the vertical axis may cause technological difficulties such as warping [28] and, when severe, also reduced strength properties [20]. Recent studies of end-user expectations on structural lumber have stressed particularly the

* Correspondence and reprints

Tel.: +46 181885 00; fax: +46 181886 00; e-mail: bjorn.hannrup@ skogforsk.se 
importance of shape stability $[18,27]$. Among the different types of distortions, twist was shown to be the most severe type in coniferous species causing downgrading or rejection of a significant proportion of the lumber [15,33]. Spiral grain is strongly associated with twist $[5,7]$ and the degree of twist may be predicted from the ratio of grain angle to the distance from the pith [1] indicating that, for a given grain angle, wood formed closer to the pith will twist more compared to wood formed far from the pith. Furthermore, in plantation-grown conifers, high grain angles are most commonly found in the juvenile wood. For instance, in Norway spruce, a left-handed spirality tend to increase from the pith outwards until a maximum has been reached at about ring number 4 , followed by a steady decrease to zero inclination or right-handed spirality $[6,25]$. Thus, decreasing grain angle is a major goal to reduce twist, especially in fast growing species with high proportions of juvenile wood.

In Norway spruce, little information is available on the genetics of spiral grain. The only published study in this species showed narrow-sense heritabilities in the range of 0.29 to 0.47 , for grain angle measured in ring numbers 11 or 12 from the pith in four trials [3]. This study also reported a low genotype by environment interaction for spiral grain and a moderate positive correlation between grain angle and stem diameter [3]. However, most published genetic parameters of grain angle in the juvenile wood are from radiata pine and Sitka spruce. For the former species, Sorensson et al. [30] concluded that the grain angle of the juvenile wood had a moderate to high heritability and a large phenotypic variation. For Sitka spruce, the narrow-sense heritability of grain angle in three trials ranged from 0.36 to 0.78 [10, 12], whereas broad-sense heritability in four trials ranged from 0.36 to 0.54 [11]. The additive genetic standard deviation was in the range between 1.3 and 1.7 degrees [10, 12]. In Sitka spruce (ring number 10) [12] and Norway spruce (ring numbers 11 or 12) [4], selection against spirality led to predicted reductions of grain angle varying between $0.5^{\circ}$ and $1.0^{\circ}$.

To develop an efficient sampling strategy for grain angles in Sitka spruce, Hansen \& Roulund [13] studied the relationship between grain angle of annual rings at $1.3 \mathrm{~m}$ above ground and whole tree grain angle values and obtained correlation coefficients ranging from 0.83 to 0.98 , between clonal means of two rings at $1.3 \mathrm{~m}$ and whole tree clonal means (mean values of all rings at 5 height levels) indicating that it is sufficient to sample ramets at one height level to obtain an accurate whole-tree value per clone. For radiata pine, Sorensson et al. [30] reached a similar conclusion and found grain angles measured in ring number 6 to 8 at $1.4 \mathrm{~m}$ above ground to be most efficient.

The aim of the present study was to estimate genetic parameters of grain angle characters in two Norway spruce clonal trials. The genetic parameters were used to calculate the expected correlated response of mean grain angle to selection for reduced grain inclination of individual rings. This provided an indication of the most efficient age to select for decreasing the average grain spirality of the juvenile wood.

\section{MATERIALS AND METHODS}

\subsection{Plant material}

Two 19-year-old (field age) clonal field trials grown at Hermanstorp $\left(56^{\circ} 45^{\prime}, 15^{\circ} 02^{\prime} ; 180 \mathrm{~m}\right.$ elevation) and Knutstorp $\left(55^{\circ} 58^{\prime}, 13^{\circ} 18^{\prime} ; 75\right.$ m elevation $)$ in southern Sweden were utilized in the study. Two-seasons old rooted cuttings were randomly planted as $2 \times 2 \mathrm{~m}$ spaced single-tree plots in five blocks with one cutting per clone and block. At Hermanstorp and Knutstorp there were 60 and 67 clones, respectively. The clones were originally selected for their superior nursery height growth in commercial seedling stocks of six Slovakian provenances. Nursery selection effects were assumed insignificant for the purpose of this study [17]. The provenances originated from a narrow geographical range, lat. $48^{\circ} 46^{\prime}-49^{\circ} 27^{\prime}$, long. $19^{\circ} 15^{\prime}-20^{\circ} 15^{\prime}$ and altitude $650-880 \mathrm{~m}$. Both trials are located on high-productive sites, formerly used as agricultural land.

Wood samples were collected from a subset of clones. All the 20 clones common to both sites were used and, in addition, a random sample was taken from clones with at least four surviving ramets per site. At Hermanstorp 182 ramets from 43 clones were used and 125 ramets from 30 clones were used at Knutstorp. Ten $\mathrm{cm}$ thick stem discs were taken from all trees at the first internode above $80 \mathrm{~cm}$.

\subsection{Measurement of spiral grain}

The first question to be considered when measuring spiral grain is the axis of reference. It is generally agreed that the grain angle refers to the angle between the longitudinal wood elements and the axis of the stem [13]. In this work the pith was used as a reference [22] and the inclination of the longitudinally wood elements against the pith can be measured with high accuracy. Also, the objectives of our study suggested to use the pith as a reference rather than the log axis [2], the latter being of more practical significance for spiral grain studies in timber [13]. The sampled disks were split using a wedge-sharped blade and a mallet to expose the pith and the grain angle on the split surface. The pith was then fixed to pins of a movable bar, which was part of a precicely manufactured protractor device (figure 1). Visibility of the grain orientation was improved by scratching the tangential surfaces along the fibres and marking these scratches with a pencil [32]. Angles were recorded with the build-in protractor and positive angles were defined as a left-handed spirality and negative one as a right-handed spirality. Sinuous stem growth [31] and other pith irregularities were not observed in the investigated trees.

\subsection{Statistical analysis}

The following measured and derived characters were included in the statistical analyses: (GA_), grain angle of individual rings in the interval of annual ring numbers 3 to 15 ; (GA3_15), arithmetic mean of the grain angle of the annual rings 3 to 15; (b_GA4_15), slope of the linear regression of grain angle on ring number from the pith for ring numbers 4 to 15 . Data from annual rings 1 to 3 were not included in the regression as these rings showed a different trend. A regression model with the logarithm of the grain angle data were 


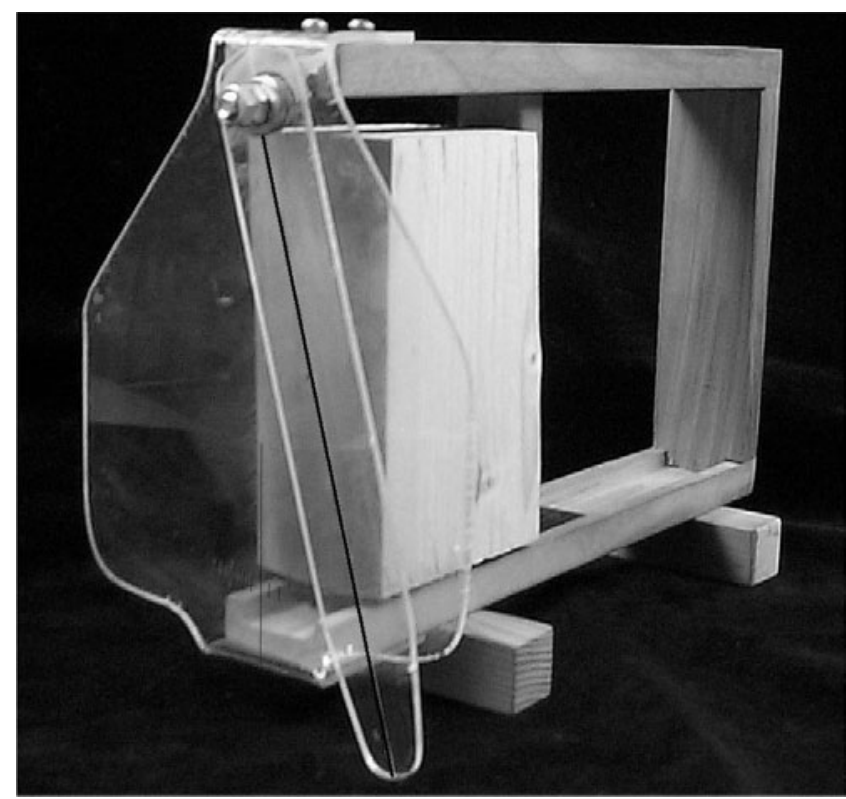

Figure 1. Apparatus to measure grain angle relative to the pith. The wooden frame has a built-in sliding bar, to which the sample is attached and aligned with the pith. Grain direction is marked on the surface and the angle is measured with the calibrated inclinometer. Grain angles were re-measured as the ring layers are sequentially removed with a chisel.

tested but rejected, as it did not provide a better fit than the model with untransformed values.

The statistical analysis was made in two steps: (i) univariate analysis, where variance components for each character within each trial were estimated; (ii) multivariate analysis, where variances and covariances between pairs of characters within trials were estimated. The following mixed linear model was used in the univariate analyses:

$$
\mathbf{y}_{1}=\mathbf{X}_{1} \mathbf{b}_{1}+\mathbf{Z}_{1} \mathbf{c}_{1}+\mathbf{e}_{1}
$$

The following two-character model, which is an extension of [1], was used in the multivariate analyses:

$$
\left[\begin{array}{l}
\mathbf{y}_{1} \\
\mathbf{y}_{2}
\end{array}\right]=\left[\begin{array}{lc}
\mathbf{X}_{1} & \mathbf{0} \\
\mathbf{0} & \mathbf{X}_{2}
\end{array}\right]\left[\begin{array}{l}
\mathbf{b}_{1} \\
\mathbf{b}_{2}
\end{array}\right]+\left[\begin{array}{ll}
\mathbf{Z}_{1} & \mathbf{0} \\
\mathbf{0} & \mathbf{Z}_{2}
\end{array}\right]\left[\begin{array}{l}
\mathbf{c}_{1} \\
\mathbf{c}_{2}
\end{array}\right]+\left[\begin{array}{l}
\mathbf{e}_{1} \\
\mathbf{e}_{2}
\end{array}\right]
$$

where $\mathbf{y}_{1}$ and $\mathbf{y}_{2}$ are observation vectors for the traits, $\mathbf{X}_{1}$ and $\mathbf{X}_{2}$ are design matrices for fixed block effects, $\mathbf{b}_{1}$ and $\mathbf{b}_{2}$ are vectors of fixed block effects, $\mathbf{Z}_{1}$ and $\mathbf{Z}_{2}$ are design matrices for random clone effects, $\mathbf{c}_{1}$ and $\mathbf{c}_{2}$ are vectors of random clone effects, $\mathbf{e}_{1}$ and $\mathbf{e}_{2}$ are vectors of random residuals.

The models did originally include the fixed effect of provenance but this effect was subsequently removed, as it turned out to be non-significant for all the grain-angle characters studied.

The random factors are assumed to be normally distributed with expectation of zero, leading to

$$
\mathbf{E}\left[\begin{array}{l}
\mathbf{y}_{1} \\
\mathbf{y}_{2}
\end{array}\right]=\left[\begin{array}{ll}
\mathbf{X}_{1} & \mathbf{b}_{1} \\
\mathbf{X}_{2} & \mathbf{b}_{2}
\end{array}\right]
$$

and with the variance-covariance matrix assumed to be

$$
\operatorname{Var}\left[\begin{array}{l}
\mathbf{c} \\
\mathbf{e}
\end{array}\right]=\left[\begin{array}{ccc}
\mathbf{G} \otimes \mathbf{I} & \mathbf{0} \\
\mathbf{0} & \mathbf{R} \otimes \mathbf{I}
\end{array}\right]
$$

where $\mathbf{G}$ is the matrix with the clonal variances and covariances, $\mathbf{R}$ is the matrix with the residual variances and covariances and $\mathbf{I}$ is an identity matrix. Finally, $\otimes$ symbolises the direct product.

The genotypic $\left(\hat{\sigma}_{\mathrm{G}}^{2}\right)$, environmental $\left(\hat{\sigma}_{\mathrm{E}}^{2}\right)$ and phenotypic $\left(\hat{\sigma}_{\mathrm{P}}^{2}\right)$ variance components were estimated as:

$$
\begin{gathered}
\left(\hat{\sigma}_{\mathrm{G}}^{2}\right)=\left(\hat{\sigma}_{\mathrm{c}}^{2}\right) \\
\left(\hat{\sigma}_{\mathrm{E}}^{2}\right)=\left(\hat{\sigma}_{\mathrm{e}}^{2}\right) \\
\left(\hat{\sigma}_{\mathrm{P}}^{2}\right)=\left(\hat{\sigma}_{\mathrm{G}}^{2}\right)+\left(\hat{\sigma}_{\mathrm{E}}^{2}\right)
\end{gathered}
$$

where $\hat{\sigma}_{\mathrm{c}}^{2}$ and $\hat{\sigma}_{\mathrm{e}}^{2}$ are the estimated clonal and residual variances, respectively.

The estimates of broad-sense heritability $\left(\hat{H}^{2}\right)$ and genotypic correlation $\left(\hat{r}_{\mathrm{g}}\right)$ between characters within sites were obtained by

$$
\hat{H}^{2}=\frac{\hat{\sigma}_{\mathrm{G}}^{2}}{\hat{\sigma}_{\mathrm{P}}^{2}} \text { and }
$$

$\hat{r}_{\mathrm{g}}=\frac{\hat{\sigma}_{\mathrm{G}_{1} \mathrm{G}_{2}}}{\hat{\sigma}_{\mathrm{G}_{1}} \hat{\sigma}_{\mathrm{G}_{2}}}$ where $\hat{\sigma}_{\mathrm{G}_{1} \mathrm{G}_{2}}$ is the estimated genotypic covariance between characters.

The statistical analysis was based on Henderson's [16] mixed model equations (MME) and variances and covariances were estimated with the Average Information algorithm [9] for restricted maximum likelihood (REML) [26, 29] estimates, as implemented in the ASReml software [8]. Estimates of the standard errors of the genetic parameters were calculated from a Taylor series approximation as performed in the ASReml software [8].

The expected correlated response (RSE) of mean grain angle in the juvenile wood to selection for grain angle of individual rings was calculated as:

$$
\mathrm{RSE}=\frac{i_{\mathrm{x}} \hat{H}_{\mathrm{x}} \hat{H}_{\mathrm{y}} \hat{r}_{\mathrm{g}} \hat{\sigma}_{\mathrm{P}_{\mathrm{y}}}}{\bar{X}_{\mathrm{y}}}
$$

where $i$ is the selection intensity, $\hat{H}$ is the square root of the broad-sense heritability, $\hat{r}_{\mathrm{g}}$ is the genotypic correlation, $\hat{\sigma}_{\mathrm{P}}$ is the phenotypic standard deviation, $\bar{X}$ is the phenotypic mean and $\mathrm{x}$ and $\mathrm{y}$ are the indices for grain angle of individual rings and mean grain angle of ring 3 to 15 , respectively. A selection intensity of 1.0 was used.

\section{RESULTS}

Starting from the pith, the mean spiral grain reached a maximum value in ring number four followed by a monotonic decrease (table I). This trend was common to both trials, with Knutstorp having higher angles in the rings closest to the pith. For the mean grain angle of rings 3 to 15 the clonal mean values ranged from 0.5 to 4.7 degrees at Hermanstorp and from -0.2 to 5.3 degrees at Knutstorp (data not shown).

The broad-sense heritability of grain angle of individual rings were moderate to high and no clear age trend was observed (table I). The trials showed identical heritability values for the mean grain angle of rings 3 to $15\left(H^{2}=0.42\right)$. The average genotypic standard deviation for grain angle of individual rings were 1.0 and 1.1 degrees at Hermanstorp and Knutstorp, respectively. The slope of the regression of grain angle on ring number from the pith was heritable, with $H^{2}$ 
Table I. Number of observations, arithmetic mean values with standard deviations in parentheses and broad-sense heritabilities with standard errors in parentheses for spiral-grain angle characters. See the Materials and Methods section for an explanation of the characters.

\begin{tabular}{|c|c|c|c|c|c|c|c|}
\hline \multirow[b]{2}{*}{ Trait } & \multirow[b]{2}{*}{ Ring no. } & \multicolumn{2}{|c|}{$\mathrm{N}$} & \multicolumn{2}{|c|}{ Mean (S.D.) } & \multicolumn{2}{|c|}{$H^{2}$ (S.E.) } \\
\hline & & Hermanstorp & Knutstorp & Hermanstorp & Knutstorp & Hermanstorp & Knutstorp \\
\hline GA_2 & 2 & 44 & 19 & $1.7(1.4)$ & $3.6(1.4)$ & $*$ & $*$ \\
\hline GA_4 & 4 & 162 & 103 & $3.8(1.3)$ & $4.1(1.7)$ & $0.30(0.09)$ & $0.44(0.11)$ \\
\hline GA_5 & 5 & 164 & 115 & $3.6(1.6)$ & $3.9(2.2)$ & $0.42(0.09)$ & $0.42(0.10)$ \\
\hline GA_6 & 6 & 167 & 115 & $3.3(1.6)$ & $3.3(2.1)$ & $0.47(0.08)$ & $0.34(0.10)$ \\
\hline GA_9 & 9 & 168 & 115 & $2.4(1.6)$ & $2.4(2.0)$ & $0.42(0.09)$ & $0.37(0.10)$ \\
\hline GA_10 & 10 & 167 & 115 & $2.1(1.6)$ & $2.1(2.0)$ & $0.41(0.08)$ & $0.40(0.10)$ \\
\hline GA_11 & 11 & 165 & 115 & $1.8(1.5)$ & $1.9(1.9)$ & $0.42(0.09)$ & $0.30(0.10)$ \\
\hline GA_12 & 12 & 166 & 114 & $1.6(1.6)$ & $1.9(2.0)$ & $0.35(0.09)$ & $0.27(0.10)$ \\
\hline GA_13 & 13 & 163 & 112 & $1.3(1.6)$ & $1.7(2.0)$ & $0.34(0.09)$ & $0.23(0.10)$ \\
\hline GA3_15 & $3-15$ & 168 & 115 & $2.4(1.4)$ & $2.6(1.6)$ & $0.42(0.08)$ & $0.42(0.10)$ \\
\hline b_GA4_15 & $4-15$ & 168 & 115 & $-0.27(0.15)$ & $-0.25(0.22)$ & $0.40(0.08)$ & $0.26(0.10)$ \\
\hline
\end{tabular}

* Not estimated due to the low number of observations.

Table II. Genotypic correlation $\left(r_{\mathrm{G}}\right)$ with standard error in parentheses between spiral-grain angle of individual year rings and mean spiral-grain angle of year ring 3 to 15 .

\begin{tabular}{llcc}
\hline & & \multicolumn{2}{c}{$r_{\mathrm{G}}$ (S.E.) } \\
\cline { 3 - 4 } Trait 1 & Trait2 & Hermanstorp & Knutstorp \\
\hline GA3 & GA3_15 & $0.50(0.20)$ & $0.52(0.23)$ \\
GA4 & GA3_15 & $0.76(0.11)$ & $0.66(0.15)$ \\
GA5 & GA3_15 & $0.85(0.06)$ & $0.90(0.07)$ \\
GA6 & GA3_15 & $0.93(0.04)$ & $1.00(0.04)$ \\
GA7 & GA3_15 & $0.95(0.03)$ & $0.92(0.05)$ \\
GA8 & GA3_15 & $0.96(0.03)$ & $0.96(0.03)$ \\
GA9 & GA3_15 & $0.97(0.02)$ & $0.98(0.03)$ \\
GA10 & GA3_15 & $0.96(0.02)$ & $0.98(0.03)$ \\
GA11 & GA3_15 & $0.99(0.01)$ & $0.88(0.07)$ \\
GA12 & GA3_15 & $0.94(0.03)$ & $0.90(0.07)$ \\
GA13 & GA3_15 & $0.93(0.03)$ & $0.89(0.09)$ \\
GA14 & GA3_15 & $0.94(0.03)$ & $0.87(0.09)$ \\
GA15 & GA3_15 & $0.89(0.05)$ & $0.86(0.10)$ \\
\hline
\end{tabular}

ranging from 0.26 at Knutstorp to 0.40 at Hermanstorp (table I).

The genotypic correlations between the grain angle of individual rings and the mean grain angle of rings 3 to 15 were high and, with exception of the two innermost rings, above 0.8 (table II). The expected correlated response in mean grain angle of rings 3 to 15 following indirect selection for grain angle of the individual rings is shown in table III. Considering both trials, the strongest correlated responses were

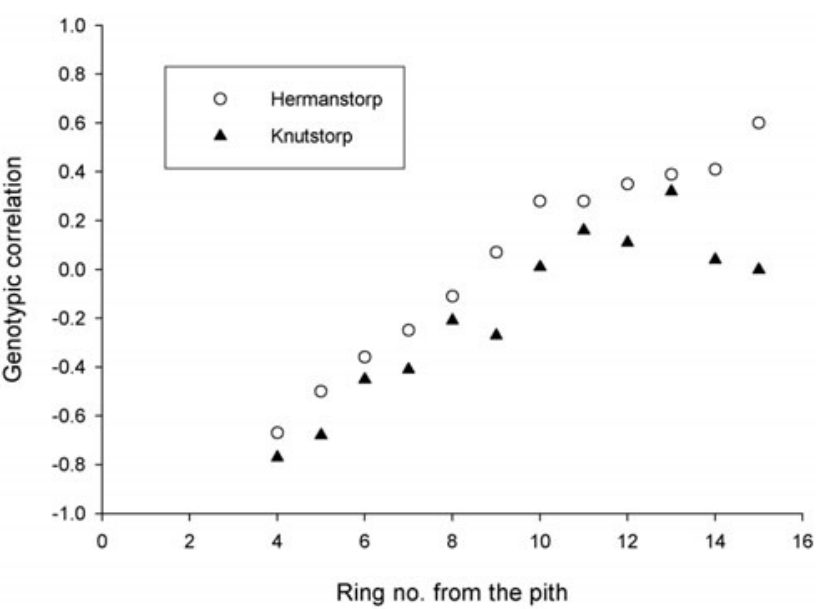

Figure 2. Genotypic correlations between the slope of the regression of grain angle on ring number from the pith and the grain angle of individual rings.

achieved when selection was based on any of the tree rings between the 5 th and the 10th ring.

The genotypic correlations between the slope of the regression of grain angle on ring number from pith and grain angle of the individual rings were highly negative in the rings closest to the pith (figure 2). This indicates that clones with high grain angle in the rings closest to the pith tended to have a more rapid development towards a straight angle in the following rings. 


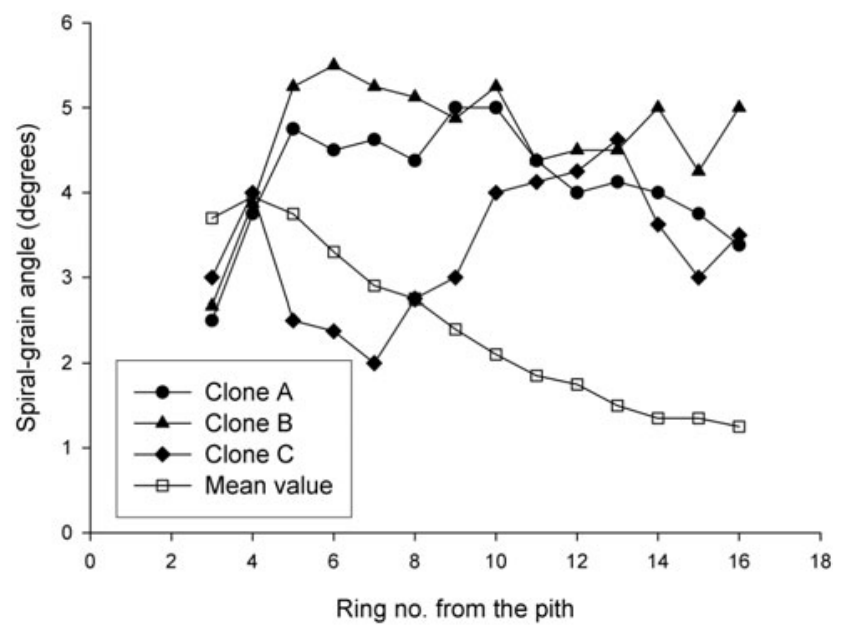

Figure 3. Mean grain angle per annual ring across trials and clonal means per ring for three clones with a tendency to retain the left-handed spirality.

Table III. Expected correlated response in mean spiral-grain angle of ring number 3 to 15 following an indirect selection based on spiral-grain angle in individual rings.

\begin{tabular}{llcc}
\hline \multirow{2}{*}{$\begin{array}{l}\text { Selection } \\
\text { trait }\end{array}$} & $\begin{array}{l}\text { Response } \\
\text { trait }\end{array}$ & \multicolumn{2}{c}{ Correlated response (\%) } \\
\cline { 3 - 4 } & & Hermanstorp & Knutstorp \\
\hline GA3 & GA3_15 & -9.2 & -11.4 \\
GA4 & GA3_15 & -15.1 & -16.9 \\
GA5 & GA3_15 & -20.0 & -22.5 \\
GA6 & GA3_15 & -23.1 & -22.5 \\
GA7 & GA3_15 & -23.6 & -23.0 \\
GA8 & GA3_15 & -22.3 & -21.9 \\
GA9 & GA3_15 & -22.8 & -23.0 \\
GA10 & GA3_15 & -22.3 & -23.9 \\
GA11 & GA3_15 & -23.2 & -18.6 \\
GA12 & GA3_15 & -20.1 & -18.1 \\
GA13 & GA3_15 & -19.6 & -16.5 \\
GA14 & GA3_15 & -21.0 & -17.8 \\
GA15 & GA3_15 & -18.0 & -18.2 \\
\hline
\end{tabular}

\section{DISCUSSION}

The tendency of spiral grain to increase outwards from the pith until a maximum after a few rings, and then followed by a gradual decrease, has been observed in spruce trees (in Sitka spruce: [13]; in Norway spruce: [6, 25]). The measured angles and peak position also agree with Danborg's study [6] in Norway spruce. In our study, the radial trends for grain angle at the two trials were similar. This may indicate similarity of the environmental conditions at the two sites, as well as the fact that several of the tested clones were common to both sites.
As clones were used, it was not possible to split the genotypic variance into additive and dominance variance. However, in the only published study reporting genetic parameters for spiral grain in Norway spruce, the results indicated that the dominating part of the genotypic variance is additive [3]. Furthermore, in the same study, the additive genetic variance for grain angle of the annual rings 11-12 ranged from 0.99 to 1.21 in three trials, and was 0.38 in a fourth trial. Under the assumption that most of the genotypic variance is additive, these results agree with the present study, where the genotypic variance for grain angle in the corresponding annual rings ranged from 0.9 to 1.1 degrees across the two trials.

The genotypic correlations between the grain angle of individual rings and the mean grain angle of rings 3-15 were generally highly positive (table II). For the sampling level considered, this indicates that an efficient selection for reduced grain angle in the juvenile wood may be accomplished by using grain angle data of individual rings. This is encouraging since there is currently no easy and non-destructive method to measure grain angle of all year rings. Noskowiak [23] was able to measure spiral angle on increment cores, which is still a semi-destructive method for young trees. The present work indicated that the strongest reduction of juvenile wood grain angles was achieved for selection based on one of the annual rings among the numbers 5 to 10 (table III). Ring numbers 5 to 10 correspond to a field age of 8 to 13 years, as it took on average 3 years for the cuttings to reach the sampling height considered. In the Swedish Norway spruce breeding program, final measurement of growth characteristics are usually carried out at a field age of 10 to 15 years. Thus, the results obtained indicate that it will be efficient to measure grain angle at the time when the growth characteristics are evaluated.

The grain angle of the outermost annual ring may be measured between two selected branch whorls or at a given height. The first type allows the generation of grain angle data with respect to cambial age and the second method with respect to the year of formation. In the present study, it was possible to analyse grain angle with respect to both cambial age and chronological year. The heritabilities for grain angle of individual rings were similar in both cases (data not shown). This indicates that, for selection purposes, it is equally efficient to base grain angle measurements either on cambial age or on the chronological year of ring formation.

The medium to high broad-sense heritabilities for grain angle in individual rings agreed with estimates obtained for Sitka spruce [11] and other conifers (for review, see [14]). Clonal differences were found in the radial pattern of grain spirality as shown by the medium to high broad-sense heritabilities for the slope of the regression of grain angle on ring number from the pith (table I). Depending on the age of selection the effect on the radial pattern will vary. The genotypic correlation between the slope of the regression of grain angle on ring number from pith and the grain angle of 
individual rings changed from being highly negative close to the pith to positive later (figure 2). In the recommended selection age interval (i.e. from ring numbers 5 to 10), the genotypic correlation was negative or non-significantly positive. This indicates that selection for low grain spirality based on any of these rings will tend to favour clones with a flat grain angle development. Whether a flat or steep grain angle development is preferable from a wood utilisation point is not clear. Further wood technological studies of this topic are needed to give guidance to breeders in identifying the target traits in order to reduce the amount of twisted lumber.

Grain angle reduction in the juvenile wood is one strategy to improve the straightness of lumber. However, it has been found that $5-10 \%$ of plantation grown Norway spruce trees retained a left-handed spirality up to the age of harvest [19, $21]$. The wood from such trees will twist severely during processing $[7,19]$. If such a grain angle pattern is under genetic control, which is presently not known, it would be of great value if genotypes retaining such a left-handed spirality could be identified and culled based on early-age measurements. In the presented material, three clones have shown a tendency to maintain left-handed spirality throughout the radius (figure 3). Two clones had high grain angles in the ring interval from 5 to 10 . A selection for low grain angle in the juvenile wood may therefore decrease the proportion of trees with constant left-handed spirality at the time of harvest. However, studies on trees older than those presently studied are needed to prove this hypothesis.

Acknowledgments: This study was supported by funds from the European Union (FAIR CT98 3953) and the Swedish Council for Forestry and Agricultural Research.

\section{REFERENCES}

[1] Balodis V., Influence of grain angle on twist in seasoned boards, Wood Sci. 5 (1972) 44-50.

[2] Brazier J.D., An assessment of the incidence and significance of spiral grain in young conifer trees, For. Prod. J. 15 (1965) 308-312.

[3] Costa E., Silva J., Borralho N.M.G., Wellendorf H., Genetic parameter estimates for diameter growth, pilodyn penetration and spiral grain in Picea abies (L.) Karst., Silvae Genet. 49 (2000) 29-36.

[4] Costa E., Silva J., Wellendorf H., Borralho N.M.G., Prediction of breeding values and expected genetic gains in diameter growth, wood density and spiral grain from parental selection in Picea abies (L.) Karst., Silvae Genet. 49 (2000) 102-109.

[5] Danborg F., Drying properties and visual grading of juvenile wood from fast grown Picea abies and Picea sitchensis, Scand. J. For. Res. 9 (1994) 91-98.

[6] Danborg F., Spiral grain in plantation trees of Picea abies, Can. J. For. Res. 24 (1994) 1662-1671.

[7] Forsberg D., Warensjö M., Grain angle variation - a major determinant of twist in sawn Picea abies (L.) Karst., Scand. J. For. Res. 16 (2001) 269-277.

[8] Gilmour A.R., Cullis B.R., Welham S.J., Thompson R., ASREML Reference Manual, Orange, Australia, 1999, 210 p.

[9] Gilmour A.R., Thompson R., Cullis B.R., Average Information REML, an efficient algorithm for variance parameter estimation in linear mixed models, Biometrics 52 (1995) 1440-1450.
[10] Hansen J.K., Genetic variation of spiral grain in Sitka spruce growing in Denmark. Multiple-trait selection for improved timber quality, Ph.D. Thesis, Royal Veterinary and Agric., Univ. Dept. of Econom. and Nat. Res. Arboretum, $1999,48 \mathrm{p}$.

[11] Hansen J.K., Roulund H., Genetic parameters for spiral grain, stem form, pilodyn and growth in 13 years old clones of Sitka spruce (Picea sitchensis (Bong.) Carr.), Silvae Genet. 46 (1997) 107-113.

[12] Hansen J.K., Roulund H., Genetic parameters for spiral grain in two 18 -year-old progeny trials with Sitka spruce in Denmark, Can. J. For. Res. 28 (1998) 920-931.

[13] Hansen J.K., Roulund H., Spiral grain in a clonal trial with Sitka spruce, Can. J. For. Res. 28 (1998) 911-919.

[14] Harris J.M., Spiral grain and wave phenomena in wood formation, Springer-Verlag, Berlin, 1989, 214 p.

[15] Haslett A.N., Simpson I.G., Kimberley M.O., Utilisation of 25-year-old Pinus radiata. Part 2: Warp of structural timber in drying, N.Z. J. For. Sci. 21 (1991) 228-234.

[16] Henderson C., Application of linear models in animal breeding, Univ. Guelph, Guelph, 1984, 462 p.

[17] Högberg K.-A., Karlsson B., Nursery selection of Picea abies clones and effects in field trials, Scand. J. For. Res. 12 (1998) 12-20.

[18] Johansson G., Kliger I.R., Perstorper M., Quality of structural timber - product specification system required by end-users, Holz Roh-Werks. 52 (1994) 42-48.

[19] Kliger R., Säll H., Prediction of twist and industrial validation. Final report subtask B9.1, FAIR CT 96-1915, Improved Spruce Timber Utilisation, Chalmers Univ. of Tech., 2000, 18 p.

[20] Kollmann F.F.P., Coté W.A., Principles of wood science and technology 1. Solid wood, Springer-Verlag, Berlin, 1984, 592 p.

[21] Krempl H., Untersuchungen über den Drehwuchs bei Fichten, Mitt. Forstl. Bundes-Versuchanstalt, Wien, 89 (1970) 117 p.

[22] Northcott P.L., Is spiral grain the normal growth pattern, For. Chron. 33 (1957) 335-352.

[23] Noskowiak A.F., Spiral grain patterns from increment cores, For. Prod. J. 18 (1968) 57-60.

[24] Panshin A.J., De Zeeuw C., Textbook on wood technology, 4th ed., McGraw Hill Book Company, New York, 1980, 722 p.

[25] Pape R., Influence of thinning on spiral grain in Norway spruce grown on highly productive sites in southern Sweden, Silva Fenn. 33 (1999) 3-12.

[26] Patterson H.D., Thompson R., Recovery of inter-block information when block sizes are unequal, Biometrika 58 (1971) 545-554.

[27] Perstorper M., Quality of structural timber - end-user requirements and performance control, Ph.D. Thesis, Dept. of Struct. Engineering, Division of Steel and Timber struct., Chalmers University, Gothenburg, 1994, 30 p.

[28] Rault J.P., Marsh E.K., The incidence and sylvicultural implication of spiral grain in Pinus longifolia, Roxb. in South Africa and its effect on converted timber, Commonwealth Forestry Conference, Canada, 1952, pp. 1-21.

[29] Schaeffer L.R., Wilton J.W., Thompson R., Simultaneous estimation of variance and covariance components from multitrait mixed model equations, Biometrics 34 (1978) 199-208.

[30] Sorensson C.T., Burdon R.D., Cown D.J., Jefferson P.A., Shelbourne C.J.A., Incorporating spiral grain into New Zealand's radiata pine breeding programme, in: Burdon R.D., Moore J.M. (Eds.), IUFRO 97, FRI, Rotorua, 1997, pp. 180-191.

[31] Spicer R., Gartner B.L., Darbyshire R.L., Sinuous stem growth in a Douglas-fir (Pseudotsuga menziesii) plantation: growth patterns and wood-quality effects, Can. J. For. Res., 30 (2000) 761-768.

[32] Tremblay C., Longitudinal and radial variation of slope of grain in black spruce lumber, For. Prod. J. 45(1995) 79-83.

[33] Woxblom L., Warp of sawn timber of Norway spruce in relation to end-user requirements. Quality sawing pattern and economic aspects, Ph.D. Thesis, Acta Univ. Agric. Sueciae, Silvestria 126. SLU, Uppsala, 1999, 119 p. 